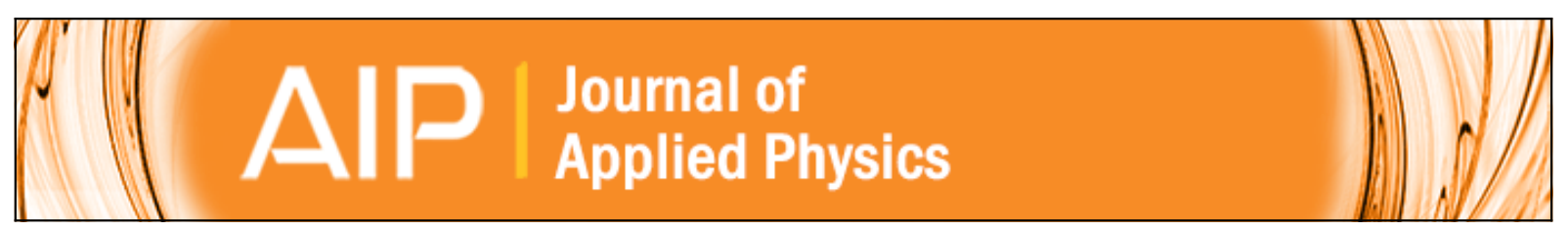

\title{
Phase transformation of ZnMoO4 by localized thermal spike
}

D. C. Agarwal, D. K. Avasthi, S. Varma, Felipe Kremer, M. C. Ridgway, and D. Kabiraj

Citation: Journal of Applied Physics 115, 163506 (2014); doi: 10.1063/1.4872259

View online: http://dx.doi.org/10.1063/1.4872259

View Table of Contents: http://scitation.aip.org/content/aip/journal/jap/115/16?ver=pdfcov

Published by the AIP Publishing

\section{Articles you may be interested in}

Effects of Au layer thickness and number of bilayers on the properties of $\mathrm{Au} / \mathrm{ZnO}$ multilayers

J. Appl. Phys. 109, 094308 (2011); 10.1063/1.3580333

Microstructure and photovoltaic performance of polycrystalline silicon thin films on temperature-stable ZnO:Al layers

J. Appl. Phys. 106, 084506 (2009); 10.1063/1.3240343

Swift heavy ion induced structural changes in CdS thin films possessing different microstructures: A comparative study

J. Appl. Phys. 106, 023508 (2009); 10.1063/1.3173180

Influence of vacuum annealing on the physical properties of $\mathrm{ZnO} / \mathrm{Al} / \mathrm{ZnO}$ multilayer coatings

J. Vac. Sci. Technol. A 27, 276 (2009); 10.1116/1.3072512

Synthesis and characterization of $\mathrm{ZnO}$ thin film grown by electron beam evaporation

J. Appl. Phys. 99, 123105 (2006); 10.1063/1.2204333

\section{A.P $\left.\right|_{\text {Applied Physics }} ^{\text {Journal of }}$}

Journal of Applied Physics is pleased to announce André Anders as its new Editor-in-Chief 


\title{
Phase transformation of $\mathrm{ZnMoO}_{4}$ by localized thermal spike
}

\author{
D. C. Agarwal, ${ }^{1}$ D. K. Avasthi, ${ }^{1}$ S. Varma, ${ }^{2}$ Felipe Kremer,${ }^{3}$ M. C. Ridgway,${ }^{3}$ and D. Kabiraj ${ }^{1}$ \\ ${ }_{1}^{1}$ Inter-University Accelerator Center, Aruna Asaf Ali Marg, New Delhi 110067, India \\ ${ }^{2}$ Institute of Physics, Sachivalaya Marg, Bhubaneswar 751005, India \\ ${ }^{3}$ Australian National University, Canberra ACT 0200, Australia
}

(Received 25 February 2014; accepted 11 April 2014; published online 23 April 2014)

\begin{abstract}
We show that $\mathrm{ZnMoO}_{4}$ remains in stable phase under thermal annealing up to $1000^{\circ} \mathrm{C}$, whereas it decomposes to $\mathrm{ZnO}$ and $\mathrm{MoO}_{3}$ under transient thermal spike induced by $100 \mathrm{MeV} \mathrm{Ag}$ irradiation. The transformation is evidenced by X-ray diffraction (XRD), Raman spectroscopy, and X-ray photoelectron spectroscopy (XPS). Thin films of $\mathrm{ZnMoO}_{4}$ were synthesized by thermal evaporation and subsequent annealing in oxygen ambient at $600{ }^{\circ} \mathrm{C}$ for $4 \mathrm{~h}$. XRD results show that as the irradiation fluence increases, the peak related to $\mathrm{ZnMoO}_{4}$ decreases gradually and eventually disappear, whereas peaks related to $\mathrm{ZnO}$ grow steadily up to fluence of $3 \times 10^{12}$ ions $/ \mathrm{cm}^{2}$ and thereafter remain stable till highest fluence. This indicates that polycrystalline $\mathrm{ZnMoO}_{4}$ film has transformed to polycrystalline $\mathrm{ZnO}$ thin film. The Raman lines related to $\mathrm{ZnMoO}_{4}$ are observed to have disappeared with increasing irradiation fluence. XPS results show modification in bonding and depletion of Mo from near surface region after the ion irradiation. Cross-sectional transmission electron microscopy result shows the formation of ion track of diameter $12-16 \mathrm{~nm}$. These results demonstrate that ion beam methods provide the means to control phase splitting of $\mathrm{ZnMoO}_{4}$ to $\mathrm{ZnO}$ and $\mathrm{MoO}_{3}$ within nanometric dimension along the ion track. The observation of phase splitting and Mo loss are explained in the framework of ion beam induced thermal spike formalism. (C) 2014 AIP Publishing LLC. [http://dx.doi.org/10.1063/1.4872259]
\end{abstract}

\section{INTRODUCTION}

Oxide materials with complex crystal structures have been subjected to swift heavy ion (SHI) irradiation for the study of the theoretical aspect of latent track formation, ${ }^{1,2}$ to introduce novel functionality, ${ }^{3,4}$ search for materials to withstand extreme conditions, ${ }^{5}$ formation of ordered structures, ${ }^{6}$ formation of controlled pinning centers in high-Tc superconductors, ${ }^{7}$ structural phase transition, ${ }^{8}$ etc. In all the cases, the modifications are driven by unique feature of thermal spike (TS), generated along the ion-track during SHI irradiation. The passage of fast charged atomic particles (heavy ions) lead to extremely strong electronic excitations inside a narrow cylinder around each ion path. The initial interaction processes of the energy transfer from a high energy heavy ion to electrons bound to inner-shells take only $10^{-19}-10^{-17}$ $\mathrm{s}$ and slightly longer (about $10^{-16} \mathrm{~s}$ ) for collective electronic excitations like formation of plasmons. ${ }^{9}$ Hence, just after the passage of the SHI, the narrow cylindrical target zone coaxial with the ion path consists of two-component plasma of "cold" lattice atoms and "hot" electrons. The energy in the electronic sub-system is transferred to phonon sub-system by electron phonon coupling to initiate thermal spike. If the temperature of the thermal spike rises above melting point of the material, the core of the track melts which extends within few nanometers in radial direction and is potentially accompanied with vaporization and pressure wave generation to the surrounding materials. The melt quenches subsequently within time scale of pico- to nanoseconds and initiates re-solidification and defect recovery. The ultra fast collective atomic rearrangement drives the local atomic structure far from equilibrium that opens up different structural phase transition pathways, which end up with equilibrium and nonequilibrium states. The region within a track consisting of modified phases, which are few nanometers in diameter and tens of micrometers in length, opens up the possibility of novel materials modification in nanometer scale and the study of nonequilibrium phase transitions. There are various observations related to resultant structural properties within the track. This includes transition from crystalline to amorphous phase, ${ }^{1}$ transition from one crystalline state to another crystalline state, like zirconia and hafnia transform from the monoclinic to the tetragonal phase, ${ }^{10}$ whereas $\mathrm{Y}_{2} \mathrm{O}_{3}$ undergoes a cubic-to-monoclinic phase transformation. ${ }^{11}$ Kluth et al. ${ }^{12}$ have reported the formation of under dense cylindrical core of the track and over dense surrounding annular region in high energy $\mathrm{Au}$ and Xe irradiated thermally grown $\mathrm{SiO}_{2}$ on $\mathrm{Si}$. The superheated core where temperature is above the boiling point surrounded by solid boundary and rapid thermal quenching along with frozen-in pressure wave which originates from the center and propagates radially outwards is described to be the cause for such observation. Natural single-crystalline zircon $\left(\mathrm{ZrSiO}_{4}\right)$ when irradiated by $\mathrm{Au}$ and $\mathrm{U}$ of energy several $\mathrm{GeV}$ under high pressure up to $14 \mathrm{GPa}$ decomposed to nano-crystals and there was nucleation of its high pressure phase, reidite. This phase formation is postulated to be due to pressure-pulse propagation around ion track. ${ }^{8}$ In case of suboxide of $\mathrm{Si}\left(\mathrm{SiO}_{\mathrm{x}}\right)$ and $\mathrm{Ge}\left(\mathrm{GeO}_{\mathrm{x}}\right)$, SHI irradiation induced phase separation is reported. $\mathrm{SiO}_{\mathrm{x}}$ and $\mathrm{GeO}_{\mathrm{x}}$ phases separate into $\mathrm{Si}$ and $\mathrm{SiO}_{2}$ and $\mathrm{Ge}$ and $\mathrm{GeO}_{2}$, respectively. ${ }^{13,14}$ Out of all the reports on SHI irradiation in oxide materials none report selective element loss. There are few reports where oxygen diffusion in molten track in $\mathrm{Fe}$ is reported to form iron oxide. ${ }^{15,16}$ Just 
opposite is observed by $\mathrm{Li}$ et al. in heavy ion irradiated Bi-2212 single crystals, where irradiation always increases hole density around the columnar defects due to oxygen deficiency. Oxygen ions, which are generated during thermal spike, are subsequently expelled from the columnar defects and the surplus of oxygen ions diffuses into the matrix. ${ }^{17}$

Here, we demonstrate that $\mathrm{ZnMoO}_{4}$ when irradiated with $100 \mathrm{MeV}$ Ag ions, phase segregates to $\mathrm{ZnO}-\mathrm{MoO}_{3}$ most probably along ion tracks due to thermal spike. As the ion fluence increases, the ion tracks overlap and finally entire thin film of $\mathrm{ZnMoO}_{4}$ degenerate to mixed phase of polycrystalline $\mathrm{ZnO}$ and a glassy state of $\mathrm{ZnO}-\mathrm{MoO}_{3}$. Complementary analytical techniques like X-ray diffraction (XRD), Raman spectroscopy, X-ray photoelectron spectroscopy (XPS), and transmission electron microscopy (TEM) were used to establish it. Scheelite-structured $\mathrm{ZnMoO}_{4}$ ternary oxide belongs to the wolframite-type metal molybdates with triclinic symmetry and has high potential applications in photoluminescence fields. ${ }^{18,19}$ Moreover, $\mathrm{ZnMoO}_{4}$ single crystals showed promising results as scintillating bolometers in high energy physics experiments. ${ }^{20}$ At low temperatures (typically $<20 \mathrm{mK}$ for large bolometers), scintillating bolometers allow simultaneous detection of scintillation light and heat which provides a very powerful tool to identify the nature of the interacting particle and therefore to suppress background. Thus, a massive charged particle can be separated from an electron or $\gamma$ due to the different light yield for the same amount of deposited heat. So the study of stability of this material under high energy ion irradiation can provide valuable information is an additional motivation for this work.

\section{EXPERIMENTAL}

$\mathrm{ZnMoO}_{4}$ thin films were grown on Si substrates by thermal heating of $\mathrm{ZnO}$ in contact with Mo. At high temperature, $\mathrm{ZnO}$ reacts with Mo and forms $\mathrm{ZnMoO}_{\mathrm{x}}(\mathrm{x}<4)$ and evaporate to form thin film. The substrates were kept at room temperature (RT) and during evaporation the chamber pressure was $5 \times 10^{-6}$ millibars. The thickness and deposition rate were monitored using a quartz crystal thickness monitor. The as-deposited films were amorphous in nature which transform to polycrystalline after annealed at $600{ }^{\circ} \mathrm{C}$ in oxygen ambient for $6 \mathrm{~h}$. These annealed thin films were uniformly bombarded with $100 \mathrm{MeV} \mathrm{Ag}$ ions at RT with different fluences using 15UD Pelletron at IUAC, New Delhi. Grazing incidence XRD (GIXRD) spectra were recorded by Bruker D8 Advance diffractometer at a grazing incidence angle of $2^{\circ}$, using a $\mathrm{CuK}_{\alpha}(1.5406 \AA)$ source operating at $40 \mathrm{kV}$ and $40 \mathrm{~mA}$. Micro-Raman measurements of pristine and irradiated films on glass substrates were performed using Renishaw in-Via Raman microscope with Ar ion laser excitation at $514 \mathrm{~nm}$. TEM was performed on cross-sectional samples using an FEI CM-300 operating at $300 \mathrm{kV}$.

\section{RESULTS AND DISCUSSION}

\section{A. X-ray diffraction}

$\mathrm{X}$-ray diffraction spectra of pristine and irradiated $\mathrm{ZnMoO}_{4}$ thin film samples are shown in Fig. 1. X-ray

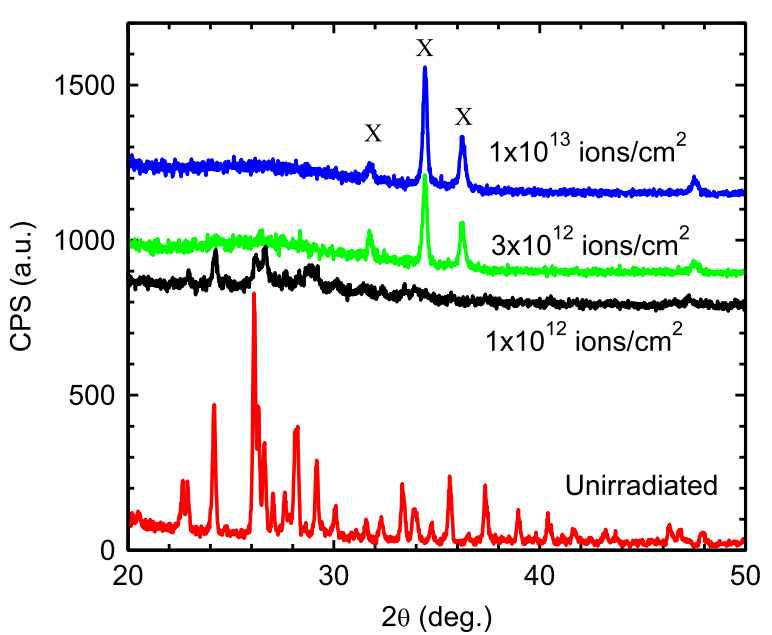

FIG. 1. XRD patterns of unirradiated $\mathrm{ZnMoO}_{4}$ and irradiated at fluences of $1 \times 10^{12}, 3 \times 10^{12}$, and $1 \times 10^{13}$ ions $/ \mathrm{cm}^{2}$. The peaks marked by $\mathrm{X}$ are related to $\mathrm{ZnO}$.

diffraction spectrum of pristine film reveals the formation of polycrystalline $\mathrm{ZnMoO}_{4}$ phase and consistent with JCPDS $72-1486\left[\mathrm{ZnMoO}_{4}\right]$. The structure of $\alpha-\mathrm{ZnMoO}_{4}$ crystals has been studied in detail by Abrahams ${ }^{21}$ who reported the crystal structure as triclinic with a space group P1 and lattice parameters of $\mathrm{a}=09625 \mathrm{~nm}, \mathrm{~b}=0.6965 \mathrm{~nm}, \mathrm{c}=0.8373 \mathrm{~nm}$, $\alpha=103.28^{\circ}, \beta=96.30^{\circ}$, and $\gamma=106.72^{\circ}$. This structure is complicated with $\mathrm{Mo}^{6+}$ ions occupying three non-equivalent positions being surrounded by four oxygen ions with approximately tetrahedral coordination. $\mathrm{Zn}^{2+}$ ions occupy sites with 5- and 6-fold coordination.

In Fig. 1, reflections related to zinc, zinc oxide, molybdenum, and molybdenum oxide phases are not observed in unirradiated sample. Ion beam irradiation of these films changes the structure gradually with increasing ion fluence and $\mathrm{ZnO}$ phase progressively evolved. Substantial decrease of the peaks related to $\mathrm{ZnMoO}_{4}$ at low fluence of $1 \times 10^{12}$ ions $/ \mathrm{cm}^{2}$ is observed. With further irradiation only three peaks with $2 \theta$ value of $31.5^{\circ}, 34.4^{\circ}$, and $36.2^{\circ}$ remain. These peaks are identified with (100), (002), and (101) reflections of $\mathrm{ZnO}$. In Figs. 2(a) and 2(b), we plot the area under the (002) reflection of $\mathrm{ZnO}$ peak and corresponding FWHM. The area increases to maximum at ion fluence of $1 \times 10^{13}$ ions $/ \mathrm{cm}^{2}$, then there is slow decrease with increasing fluence till the highest fluence of $7 \times 10^{13}$ ions $/ \mathrm{cm}^{2}$. The FWHM follows the opposite trend, indicates the grain size is maximum at $1 \times 10^{13}$ ions $/ \mathrm{cm}^{2}$ then potentially fragmentation of grains at higher irradiation fluences and associated increase of amorphous fraction at grain boundaries as reflected in decrease of area under the peak. Grain fragmentation is reported to be cause of increase in width of XRD peak of nonamorphizable material $\mathrm{CaF}_{2}$ under thermal spike. ${ }^{22}$ Minimal change in the position of the centroid is observed, which indicates that crystal structure is not modified due to irradiation.

\section{B. Micro-Raman spectroscopy}

The samples were further characterized by Raman spectroscopy to corroborate observed XRD results showing 


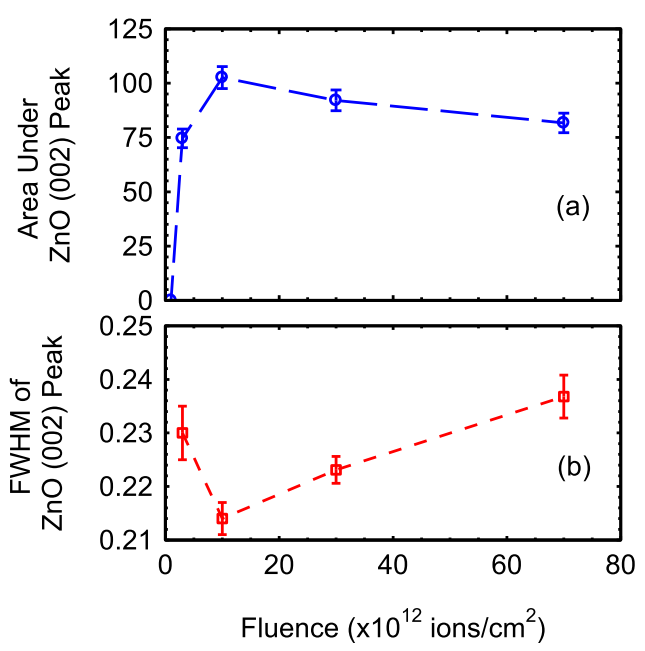

FIG. 2. (a) Area under $\mathrm{ZnO}$ (002) peak plotted against irradiation fluence. (b) FWHM of the same peak plotted against irradiation fluence. Connecting lines are guide to eye.

formation of polycrystalline $\mathrm{ZnO}$ after irradiation. The measured Raman spectra of pristine and irradiated $\mathrm{ZnMoO}_{4}$ thin film samples are shown in Fig. 3. Raman spectrum of pristine film exhibits the characteristic nature of metal molybdate, and the peaks match well with the $\alpha-\mathrm{ZnMoO}_{4}$ formed in $\mathrm{ZnO}-\mathrm{MoO}_{3}-\mathrm{B}_{2} \mathrm{O}_{3}$ glass as reported by Aleksandrov et al. ${ }^{23}$ Raman scattering spectra show several sharp peaks which match well with the result reported in Ref. 23, at 340, 370, $405,787,818,849,860,882,890,930,947$, and $970 \mathrm{~cm}^{-1}$. $\mathrm{MoO}_{n}$ polyhedra, i.e., $\mathrm{MoO}_{4}$ tetrahedra and $\mathrm{MoO}_{6}$ octrahedra, are known ${ }^{24}$ to give strong Raman bands where band between 300 and $450 \mathrm{~cm}^{-1}$ is related to symmetric and anti-symmetric bending modes and between 750 and $1100 \mathrm{~cm}^{-1}$ is related to symmetric and anti-symmetric stretching modes. The peaks at 301,520 , and $618 \mathrm{~cm}^{-1}$ originate from $\mathrm{Si}$ substrate. After irradiation, all the Raman peaks disappear except a small hump at $330 \mathrm{~cm}^{-1}$ and a

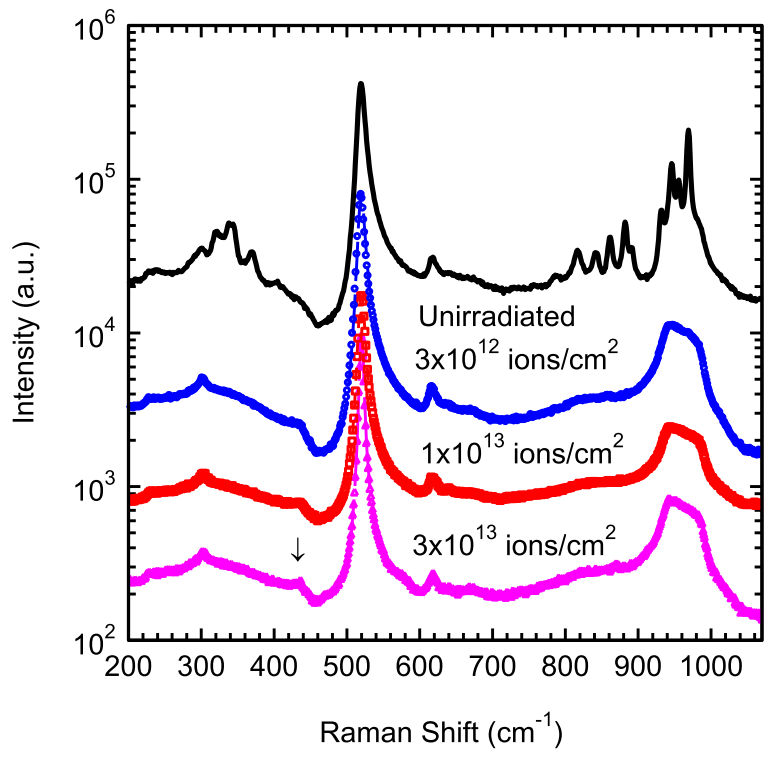

FIG. 3. Raman scattering spectra of unirradiated $\mathrm{ZnMoO}_{4}$ and irradiated at fluences of $3 \times 10^{12}, 1 \times 10^{13}$, and $3 \times 10^{13} \mathrm{ions} / \mathrm{cm}^{2}$. The peak at $436.97 \mathrm{~cm}^{-1}$ evolved in irradiated samples is shown by $(\downarrow)$. bigger one at $960 \mathrm{~cm}^{-1}$. This is exactly opposite to what observed by Aleksandrov et al., ${ }^{23}$ where these two bands appear in amorphous glassy state and convert to sharp peaks when annealed to form crystalline $\alpha-\mathrm{ZnMoO}_{4}$. So we can infer that after irradiation, the crystalline phase converts to glassy amorphous phase of $\mathrm{ZnO}-\mathrm{MoO}_{3}$. The peak at $436.97 \mathrm{~cm}^{-1}$ evolved in irradiated samples, which is identified with $\mathrm{E}_{2}$-high mode of $\mathrm{ZnO}$, a characteristic feature of wurtzite structure of $\mathrm{ZnO}$. The results indicate the irradiated thin films have two components: (i) crystalline $\mathrm{ZnO}$ phase, observed both in XRD and Raman spectroscopy and (ii) glassy amorphous phase $\mathrm{ZnO}-\mathrm{MoO}_{3}$ which is only observed by Raman spectroscopy.

\section{X-ray photoelectron spectroscopy}

$\mathrm{X}$-ray photoelectron spectroscopy measurements have been performed to determine the elemental composition and oxidation state of elements. Carbon peak is used to calibrate the acquired spectra and the position of $\mathrm{C} 1 \mathrm{~s}$ peak is located at binding energy of $284.6 \mathrm{eV}$. XPS spectra showing Mo $3 \mathrm{~d}$ levels of pristine and irradiated samples are shown in Fig. 4(a). The doublet of Mo 3d peak appears at 232.4 and $235.6 \mathrm{eV}$, which corresponds to Mo $3 \mathrm{~d}^{5 / 2}$ and $3 \mathrm{~d}^{3 / 2}$,
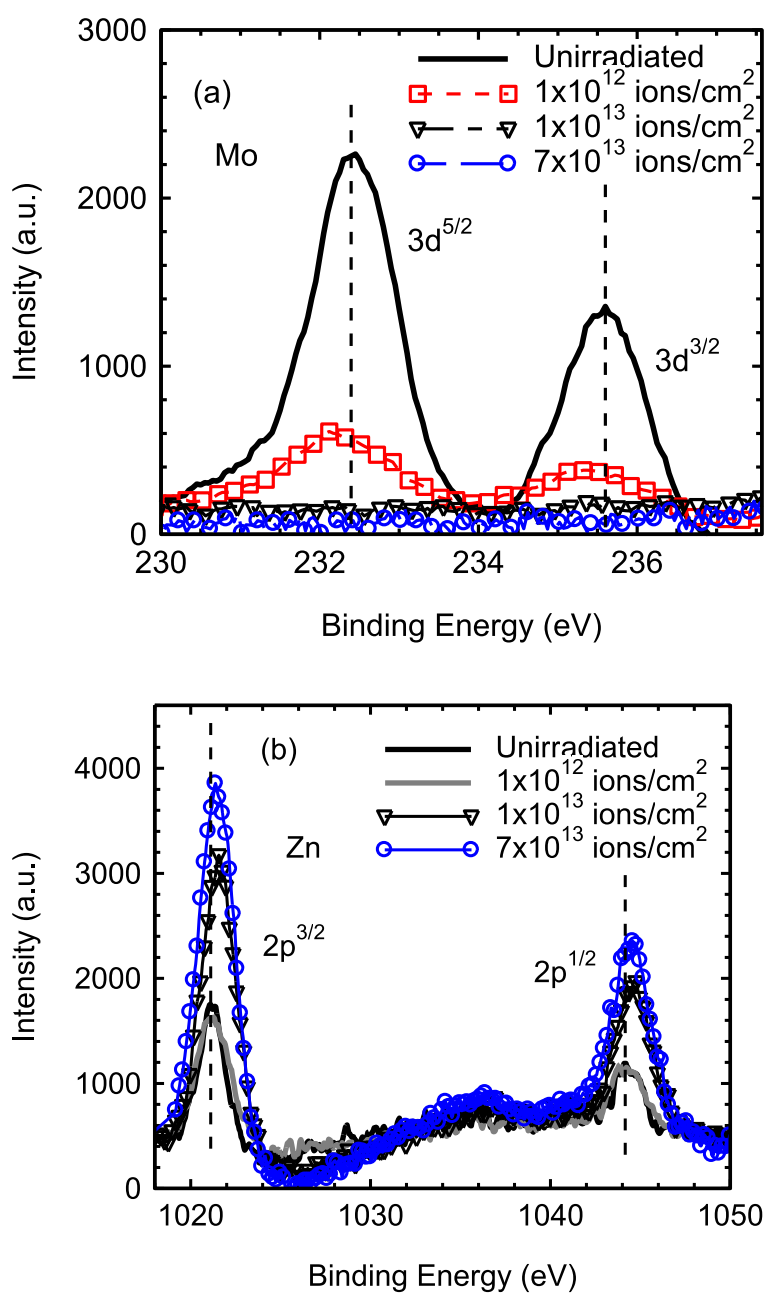

FIG. 4. XPS spectra of unirradiated and irradiated samples related to Mo $3 \mathrm{~d}$ and $\mathrm{Zn} 2 \mathrm{p}$ are shown in (a) and (b), respectively. 
respectively. As a result of spin-orbit splitting of Mo $3 \mathrm{~d}$ level is giving rise to $3 \mathrm{~d}^{5 / 2}$ and $3 \mathrm{~d}^{3 / 2}$ levels with an energy separation of $3.2 \mathrm{eV}$, which is well matched with the present result. Near Gaussian shape of the Mo $3 \mathrm{~d}^{5 / 2}$ peak indicates that most of Mo is present in +6 charge state. ${ }^{25,26} \mathrm{Zn} 2 \mathrm{p}^{3 / 2}$ and $2 \mathrm{p}^{1 / 2}$ peaks are present at $1021.1 \mathrm{eV}$ and $1044.2 \mathrm{eV}$ in the pristine sample as can be seen in Fig. 4(b). In irradiated samples, there is not much change in the shape of the peaks related to $\mathrm{Zn}$. In the $1 \times 10^{12}$ ions $/ \mathrm{cm}^{2}$ irradiated sample, there is substantial decrease of Mo peaks and shift to lower binding energy side. In samples irradiated at higher fluences, these Mo related features are absent. It confirms that there is loss of Mo at least up to the probing depth of XPS which is few nm only. Although after an irradiation with $1 \times 10^{12}$ ions $/ \mathrm{cm}^{2}, \mathrm{Zn}$ $2 \mathrm{p}^{3 / 2}$ and $2 \mathrm{p}^{1 / 2}$ features display similar intensity as un-irradiated sample, they become stronger with increasing fluence. Moreover, at higher fluences $\left(1 \times 10^{13}\right.$ and $7 \times 10^{13}$ ions $/ \mathrm{cm}^{2}$ ), these $\mathrm{Zn}$ related peaks shift towards higher binding energies (see Fig. 4(b)). These shifts are consistent with the formation of $\mathrm{ZnO}$ at high fluences.

\section{Transmission electron microscopy}

Fig. 5 shows the cross section TEM of $\mathrm{ZnMoO}_{4}$ film sample irradiated at $5 \times 10^{10}$ ions $/ \mathrm{cm}^{2}$. The bright field image was obtained with the electron beam aligned to the $\mathrm{Si}\langle 110\rangle$ direction of the Si substrate, parallel to the $\mathrm{ZnMoO}_{4} / \mathrm{Si}(001)$ interface. The apparent formation of ion tracks of diameter $12-16 \mathrm{~nm}$ is seen in TEM image. With average track diameter of $14 \mathrm{~nm}$, the fluence at which the tracks start overlapping is $\sim 6 \times 10^{11}$ ions $/ \mathrm{cm}^{2}$, this is consistent with our XRD, Raman, and XPS results where we observe appreciable changes due to phase transition around this fluence.

The inelastic TS model (I-TS) is commonly used to describe swift heavy ion interactions with matter. ${ }^{27}$ Within this framework, the ion irradiation is treated in a three-step model. In the first step, the electronic stopping power $\left(S_{e}\right)$ of

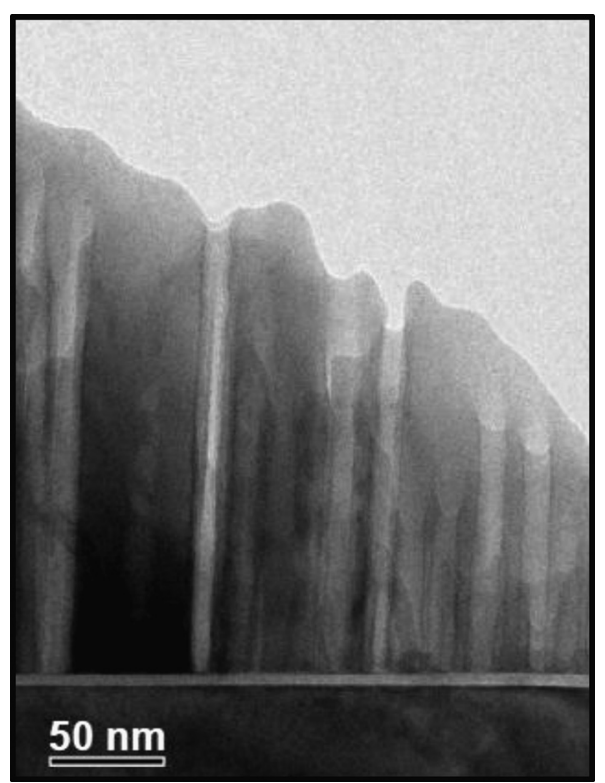

FIG. 5. Cross section TEM from irradiated at fluence of $5 \times 10^{10} \mathrm{ions} / \mathrm{cm}^{2}$. the ion is used to excite the target electron system. In Figure 5 (b), along the ion track of $200 \mathrm{~nm}$ the average $S_{e}$ is $\sim 16 \mathrm{keV} / \mathrm{nm}$. Then, the excited electrons propagate diffusively through the target. For a given material and $S_{e}$, the final effect strongly depends on the radial distribution of energy density. The energy stored in the electronic system is then transferred to the phonon system via electron-phonon coupling and finally leads to thermal spike. The electron-phonon coupling parameter g controls the flux of heat or energy from the electrons to the phonons per unit time and volume. This parameter governs the heating of the lattice and is thus a crucial quantity. The mathematical description is therefore based on a set of two coupled heat diffusion equations, one for the electron system and one for the phonon system.

A complete set of lattice thermodynamic parameters required to estimate the spike temperature using I-TS model is not available for $\mathrm{ZnMoO}_{4}$ to best of our knowledge. The published experimental and theoretical understanding help us to explain that average electronic energy loss of $16 \mathrm{keV} / \mathrm{nm}$ deposited by $100 \mathrm{MeV} \mathrm{Ag}(\sim 1 \mathrm{MeV} / \mathrm{amu})$ can generate thermal spike to initiate track formation and material loss in $\mathrm{ZnMoO}_{4}$ thin film. The effects of electronic stopping power in materials modification are non-liner and appear when the energy loss surpass threshold value. After stopping power exceeds threshold value, the track formation is observed in amorphizable material when track temperature is raised above melting point. On the other hand nonamorphizable materials, like materials with ionic bonding $\mathrm{LiF}$, $\mathrm{CaF}_{2}$, the track is observed when temperature exceeds vaporization temperature. $^{22}$

Only limited experimental data are available on the electron-phonon coupling parameter for dielectrics, which is therefore often treated as a fitting parameter. It is related to electron-lattice interaction mean free path $\lambda\left(\lambda^{2}=\mathrm{A} / \mathrm{g}\right.$ with $\mathrm{A}=2 \mathrm{~J} / \mathrm{s} / \mathrm{cm} / \mathrm{K}$ ) defined as the mean length of the energy diffusion within the electron system before the energy is transferred to lattice. The cutoff of the energy spread is restricted by the minimum ionization energy, that is, when electron energy is less than this energy. Here comes the link between the values of $\lambda$ and band gap energy $\left(E_{\mathrm{g}}\right)$, which is the minimum ionization energy of electron in insulators. The values of $\lambda$ for various insulators are evaluated by fitting experimentally observed track diameter and plotted against $\mathrm{E}_{\mathrm{g}}$ in Ref. 1 . The graph shows that, for $\mathrm{E}_{\mathrm{g}}$ larger than $2.8 \mathrm{eV}$, there is only a slight decrease of $\lambda$ from 5 to $4 \mathrm{~nm}$. This indicates that in crystalline insulators the electron energy transfer towards the atoms happen in nearly same way. ${ }^{28,29} \mathrm{Y}_{3} \mathrm{Fe}_{5} \mathrm{O}_{12}$ is a ferromagnetic insulator with band gap of $2.85 \mathrm{eV}$ having complex garnet structure. $\mathrm{ZnMoO}_{4}$ is a wide band gap insulator with $4.17 \mathrm{eV}<\mathrm{E}_{\mathrm{g}}<5.35 \mathrm{eV}$ having complex molybdate structure with both having no congruent melt phase is expected to yield similar result under thermal spike. ${ }^{30}$ It is reported that tracks appear in $\mathrm{Y}_{3} \mathrm{Fe}_{5} \mathrm{O}_{12}$ when $S_{e}$ is above $4 \mathrm{keV} / \mathrm{nm}$ and the sputtering above $16 \mathrm{keV} / \mathrm{nm}^{31,32}$ This experimental observation indicates that track temperature reached above vaporization temperature in $\mathrm{Y}_{3} \mathrm{Fe}_{5} \mathrm{O}_{12} S_{e} \sim 16 \mathrm{keV} / \mathrm{nm}$. With analogy given above, one can expect that electronic energy loss of $16 \mathrm{keV} / \mathrm{nm}$ is sufficient to raise the track temperature above melting point of $\mathrm{ZnMoO}_{4}$. 
We estimate the energy per atom for $100 \mathrm{MeV} \mathrm{Ag}$ irradiated $\mathrm{ZnMoO}_{4}$ within cylindrical track volume of radius $R=6.0 \mathrm{~nm}$ and length $1 \mathrm{~nm}$ the mean deposited energy per atom can be evaluated as shown in Ref. 22

$$
E_{\text {atom }} S_{e} /\left(\pi \times R^{2} \times N_{\text {atom }}\right) .
$$

In case of $\mathrm{ZnMoO}_{4}$, atomic density $N_{\text {atom }}$ is $6.9 \times 10^{22}$ atoms $/ \mathrm{cm}^{3}$ and $S_{e}$ is electronic energy loss at the corresponding beam energy, in this case it is $16 \mathrm{keV} / \mathrm{nm}$. Equation (1) gives the value of $E_{\text {atom }}=2.0 \mathrm{eV} / \mathrm{at}$. Our calculation shows that $100 \mathrm{MeV}$ Ag irradiation of $\mathrm{ZnMoO}_{4}$ which has melting point of $1007 \pm 2{ }^{\circ} \mathrm{C},,^{33,34}$ energy gain per atom $\sim 2.0 \mathrm{eV}$ should raise track temperature to above melting point.

$\mathrm{ZnMoO}_{4}$ incongruently melts to $\mathrm{ZnO}$ and $\mathrm{MoO}_{3}$ at $\sim 1007 \pm 2{ }^{\circ} \mathrm{C}^{33,34}$ indicates that when thermal spike temperature exceeds this point such reaction occurs within the track volume. Very interesting of this system is that the one component of melt product $\mathrm{MoO}_{3}$ has lower melting point $\left(\sim 795^{\circ} \mathrm{C}\right.$ ) and the other component $\mathrm{ZnO}$ has much higher melting point $\left(1975^{\circ} \mathrm{C}\right)$ than $\mathrm{ZnMoO}_{4} \cdot{ }^{32}$ The boiling point of $\mathrm{MoO}_{3}$ is $1155^{\circ} \mathrm{C}$, which is close to the melting point of $\mathrm{ZnMoO}_{4}$, may results in its ejection out of the track, which explains the loss of Mo in near surface region as observed in XPS measurement. In the subsurface region, during cooling of the ion track, the $\mathrm{MoO}_{3}$ solidifies in amorphous glassy phase so could not be observed in XRD spectrum (Fig. 1) but appeared as humps in Raman spectroscopy (Fig. 3). On the other hand, after phase separation during thermal spike, $\mathrm{ZnO}$ with inter-atomic bonding being highly ionic in nature remain in polycrystalline form as shown in XRD and Raman spectroscopy (Figs. 1 and 3).

\section{CONCLUSIONS}

We have demonstrated that phase segregation of $\mathrm{ZnMoO}_{4}$ takes place due to $100 \mathrm{MeV}$ Ag irradiation. The proposed mechanism of formation of glassy $\mathrm{ZnO}-\mathrm{MoO}_{3}$ phase is due to incongruent melting of $\mathrm{ZnMoO}_{4}$ during transient molten phase. $\mathrm{ZnO}$ solidifies in polycrystalline form as observed by XRD. XPS measurement indicates loss of Mo from near surface region is attributed to vaporization of $\mathrm{MoO}_{3}$, as its boiling temperature is close to the melting point of $\mathrm{ZnMoO}_{4}$.

\section{ACKNOWLEDGMENTS}

We thankfully acknowledge Pelletron group, InterUniversity Accelerator Centre for delivering stable beam for irradiation. We also acknowledge Professor Anushree Roy, IIT Kharagpur for micro-Raman measurement and Mr. Santosh Choudhury of Institute of Physics, Bhubaneswar who has taken XPS.
${ }^{1}$ M. Toulemonde, Ch. Dufour, A. Meftah, and E. Paumier, Nucl. Instrum. Methods Phys. Res., Sect. B 166-167, 903 (2000).

${ }^{2}$ M. Toulemonde, W. J. Weber, G. Li, V. Shutthanandan, P. Kluth, T. Yang, Y. Wang, and Y. Zhang, Phys. Rev. B 83, 054106 (2011).

${ }^{3}$ K.-i. Nomura, M. Fujimaki, K. Awazu, and T. Komatsubara, J. Vac. Sci. Technol., A 29, 051402 (2011).

${ }^{4}$ A. Dallanora, T. L. Marcondes, G. G. Bermudez, P. F. P. Fichtner, C. Trautmann, M. Toulemonde, and R. M. Papaléo, J. Appl. Phys. 104, 024307 (2008).

${ }^{5}$ J. Zhang, M. Lang, R. C. Ewing, R. Devanathan, W. J. Weber, and M. Toulemonde, J. Mater. Res. 25, 1344 (2010).

${ }^{6}$ W. Bolse, Nucl. Instrum. Methods Phys. Res., Sect. B 244, 8 (2006).

${ }^{7}$ Y. Zhu, Z. X. Cai, R. C. Budhani, M. Suenaga, and D. O. Welch, Phys. Rev. B 48, 6436 (1993).

${ }^{8}$ U. A. Glasmacher, M. Lang, H. Keppler, F. Langenhorst, R. Neumann, D. Schardt, C. Trautmann, and G. A. Wagner, Phys. Rev. Lett. 96, 195701 (2006).

${ }^{9}$ G. Schiwietz, K. Czerski, M. Roth, F. Staufenbiel, and P. L. Grande, Nucl. Instrum. Methods Phys. Res., Sect. B 226, 683 (2004).

${ }^{10}$ A. Benyagoub, Phys. Rev. B 72, 094114 (2005).

${ }^{11}$ S. Hémon, V. Chailley, E. Dooryhee, C. Dufour, F. Gourbilleau, F. Levesque, and E. Paumier, Nucl. Instrum. Methods Phys. Res., Sect. B 122, 563 (1997).

${ }^{12}$ P. Kluth, C. S. Schnohr, O. H. Pakarinen, F. Djurabekova, D. J. Sprouster, R. Giulian, M. C. Ridgway, A. P. Byrne, C. Trautmann, D. J. Cookson, K. Nordlund, and M. Toulemonde, Phys. Rev. Lett. 101, 175503 (2008).

${ }^{13}$ W. M. Arnoldbik, N. Tomozeiu, E. D. van Hattum, R. W. Lof, A. M. Vredenberg, and F. H. P. M. Habraken, Phys. Rev. B 71, 125329 (2005).

${ }^{14}$ Y. Batra, D. Kabiraj, S. Kumar, and D. Kanjilal, J. Phys. D: Appl. Phys. 40, 4568 (2007).

${ }^{15}$ T. Roller and W. Bolse, Phys. Rev. B 75, 054107 (2007).

${ }^{16}$ D. K. Avasthi, W. Assmann, A. Tripathi, S. K. Srivastava, S. Ghosh, F. Grüner, and M. Toulemonde, Phys. Rev. B 68, 153106 (2003).

${ }^{17}$ M. Li, C. J. van der Beek, M. Konczykowski, H. W. Zandbergen, and P. H. Kes, Phys. Rev. B 66, 014535 (2002).

${ }^{18}$ R. Graser, E. Pitt, A. Scharmann, and G. Zimmerer, Phys. Status Solidi B 69, 359 (1975).

${ }^{19}$ J. Ryu, S. Koo, J. Yoon, C. Lim, and K. Shim, Mater. Lett. 60, 1702 (2006).

${ }^{20}$ J. W. Beeman et al., Phys. Lett. B 710, 318 (2012).

${ }^{21}$ S. C. Abrahams, J. Chem. Phys. 46, 2052 (1967).

${ }^{22}$ M. Toulemonde, A. Benyagoub, C. Trautmann, N. Khalfaoui, M. Boccanfuso, C. Dufour, F. Gourbilleau, J. J. Grob, J. P. Stoquert, J. M. Costantini, F. Haas, E. Jacquet, K.-O. Voss, and A. Meftah, Phys. Rev. B 85, 054112 (2012).

${ }^{23}$ L. Aleksandrov, T. Komatsu, R. Iordanova, and Y. Dimitriev, Opt. Mater. 33, 839 (2011).

${ }^{24}$ C. Luz-Lima, G. D. Saraiva, A. G. S. Filho, W. Paraguassu, P. T. C. Freire, and J. M. Filho, J. Raman Spectrosc. 41, 576 (2010).

${ }^{25}$ X. Fan, G. Fang, P. Qin, N. Sun, N. Liu, Q. Zheng, F. Cheng, L. Yuan, and X. Zhao, J. Phys. D: Appl. Phys. 44, 045101 (2011).

${ }^{26}$ M. F. Al-Kuhaili, S. M. A. Durrani, I. A. Bakhtiari, and A. M. Al-Shukri, Opt. Commun. 283, 2857 (2010).

${ }^{27}$ M. Toulemonde, C. Dufour, and E. Paumier, Phys. Rev. B 46, 14362 (1992).

${ }^{28}$ G. Szenes, Phys. Rev. B 51, 8026 (1995).

${ }^{29}$ G. Szenes, Phys. Rev. B 52, 6154 (1995).

${ }^{30}$ D. Spassky, A. Vasil'ev, I. Kamenskikh, V. Kolobanov, V. Mikhailin, A. Savon, L. Ivleva, I. Voronina, and L. Berezovskaya, Phys. Status Solidi A 206(7), 1579-1583 (2009).

${ }^{31}$ A. Meftah, F. Brisard, J. M. Costantini, M. Hage-Ali, J. P. Stoquert, F. Studer, and M. Toulemonde, Phys. Rev. B 48, 920 (1993).

${ }^{32}$ A. Meftah, M. Djebarra, J. P. Stoquert, F. Studer, and M. Toulemonde, Nucl. Instrum. Methods Phys. Res., Sect. B 107, 242 (1996).

${ }^{33}$ T. Söhnel, W. Reichelt, H. Oppermann, Hj. Mattaush, and A. Simon, Z. Anorg. Allg. Chem. 622, 1274 (1996).

${ }^{34}$ L. I. Ivleva, I. S. Voronina, L. Yu. Berezovskaya, P. A. Lykov, V. V. Osiko, and L. D. Iskhakova, Crystallogr. Rep. 53, 1087 (2008). 